\title{
Young People as Drivers or Inhibitors of the Sustainability Movement: The Case of Anti-Consumption
}

\author{
F. Ziesemer ${ }^{1}$ (D) A. Hüttel ${ }^{1}$ (D) I. Balderjahn ${ }^{1}$
}

Received: 16 November 2020 / Accepted: 13 April 2021/ Published online: 15 May 2021

(C) The Author(s) 2021

\begin{abstract}
As overconsumption has negative effects on ecological balance, social equality, and individual well-being, reducing consumption levels among the materially affluent is an emerging strategy for sustainable development. Today's youth form a crucial target group for intervening in unsustainable overconsumption habits and for setting the path and ideas on responsible living. This article explores young people's motivations for engaging in three behavioural patterns linked to anti-consumption (voluntary simplicity, collaborative consumption, and living within one's means) in relation to sustainability. Applying a qualitative approach, laddering interviews reveal the consequences and values behind the anti-consumption behaviours of young people of ages 14 to 24 according to a means-end chains analysis. The findings highlight potential for and the challenges involved in motivating young people to reduce material levels of consumption for the sake of sustainability. Related consumer policy tools from the fields of education and communication are identified. This article provides practical implications for policy makers, activists, and educators. Consumer policies may strengthen anti-consumption among young people by addressing individual benefits, enabling reflection on personal values, and referencing credible narratives. The presented insights can help give a voice to young consumers, who struggle to establish themselves as key players in shaping the future consumption regime.
\end{abstract}

Keywords Voluntary simplicity · Collaborative consumption · Sustainable consumption · Meansend chain analysis $\cdot$ Laddering interviews $\cdot$ Youth

A new global youth movement emerged in autumn of 2018. United by a shared concern to sustain humankind's future on planet Earth, students worldwide started skipping school on

F. Ziesemer

florence.ziesemer@uni-potsdam.de

1 Department of Marketing, University of Potsdam, August-Bebel-Straße 89, 14482, Potsdam, Germany 
Fridays to publicly demonstrate their requests for impactful actions against climate change. Although the long-lasting impact of this so-called Fridays for Future movement on policymaking still needs to be proven, it suggests that young people not only take on environmental responsibility as political citizens but might increasingly use opportunities to engage as sustainability conscious consumers. Today's youth constitute a generation that must confront the challenging environmental, societal, and economic conditions created in previous decades (Fien et al. 2008). They therefore represent a crucial target group for intervening against unsustainable consumption habits and for setting the path for the development of means for more responsible living (Fischer et al. 2017; Francis and Davis 2015; Grauerholz and Bubriski-McKenzie 2012; Kamenidou et al. 2019; UNESCO-UNEP 2007).

Since human activities cause environmental degradation and global warming (Cook et al. 2016), sustainable consumption and production have been established as one of the United Nations' Sustainable Development Goals (United Nations 2015). In the search for a holistic perspective on such issues and suitable solutions, a long-standing focus on rather conventional efficiency-focused strategies based on technological innovation is increasingly being challenged by approaches to reduce absolute consumption levels among materially affluent consumers in both rich and poor nations (Greening et al. 2000; Jackson 2005a; Lorek and Fuchs 2013; Prothero et al. 2011; Schneider et al. 2010). Strategies for counteracting unsustainable practices of overconsumption and achieving the double dividend of "living better by consuming less" (Jackson 2005a) meet systemic challenges which require synthesized action in politics, economics, civil society, and by individuals (Assadourian 2010). For individuals, reducing their consumption levels appears as the responsible thing to do, yet this objective resembles a rebellious act within a still consumption-focused society. In this way, anticonsumption serves as a valuable subject for transformative science (Kozinets et al. 2010). Long studied as a multi-faceted concept, anti-consumption implies the intentional and meaningful avoidance of consuming goods (Makri et al. 2020) with potentially positive effects on sustainability.

In this paper, we focus on the young population, which has rarely been the focus of sustainability-focused anti-consumption research. The young exhibit unique characteristics regarding consumption (Mau et al. 2014; Te'eni-Harari 2014). Teenagers and young adults are in transition from childhood to adulthood and commonly defined by the United Nations (2018) as "youth" or interchangeably "young people" of ages 15 to 24. Young people, not yet mature but no longer minors, develop sophisticated skills and more critical attitudes to navigate their activities as consumers in the marketplace while using autonomous, self-directed consumption as part of their identity creation (Palan et al. 2010). Torn between a role as potential change makers and seeking stability within the commercial status quo, young people are a promising yet challenging group to engage in anti-consumption (de Araujo Gil et al. 2016). Therefore, young people, often culturally framed as rebels against the mainstream, are an exciting group for investigating anti-consumption, which is commonly studied in context of consumer resistance (Cherrier et al. 2012) against the dominant social paradigm (Gorge et al. 2015). Nevertheless, little is known about the motivations that shape young people's decision-making concerning anti-consumption. This is a potential barrier to enhance their practice of sustainable consumption. Therefore, the questions of what motives might lead young people to practice anti-consumption, and how these motives relate to sustainability, guide this study.

An important prerequisite to understand motives is that consumption acts are rarely a desired end in themselves, but according to means-end chain theory, a means to achieve functional or symbolic goals (Gutman 1982). This implies that behind every 
(anti-)consumption decision lies a cognitive process connecting attributes of a choice set with anticipated consequences and underlying personal values (Aurifeille and Florence 1995; Grunert and Grunert 1995; Reynolds and Gutman 1988). To achieve better understanding of why people choose not to consume, knowledge about such cognitive processes is useful (Hüttel et al. 2020; Jackson 2005b). It consecutively helps creating strategies that strengthen anti-consumption patterns publicly and successfully address the target group (Beldad and Hegner 2018; Lundblad and Davies 2016; Steinmetz et al. 2016). Despite limits to how much factors and processes internal to the individual can explain a specific behaviour (Pravet and Holmlund 2018; Thøgersen 2010), values play a significant role in predicting specific beliefs and behaviours (Rokeach 1973; Schwartz and Bilsky 1987), are more effective in explaining consumer behaviour than demographics alone (de Pelsmacker et al. 2005), and are relevant determinants of pro-environmental behaviour (e.g., Kadic-Maglajlic et al. 2019; Matthies and Wallis 2015; Thøgersen and Ölander 2002). For instance, studies show significant interactions between personal values and consciousness for sustainable consumption (Balderjahn and Hüttel 2019), sustainable fashion (Lundblad and Davies 2016), socially conscious consumption (Pepper et al. 2009), and fair-trade consumption (Doran 2009). Building on these premises and means-end chain theory, our research aims to extend these perspectives for anti-consumption and thereby to display the relative importance of different motives among young people.

Considering our research topic's novelty and complexity, as well as motivations assumed to be unique for the target group, a qualitative approach for exploratory research is appropriate. We apply the laddering interview technique in personal in-depth interviews with German youths which helps to identify the consequences and values that motivate their behaviours concerning anti-consumption. To further determine how young people may activate their potential as anti-consumers, this research addresses the following questions: What perceived consequences and values motivate young people to engage in anti-consumption patterns? What policy tools can facilitate anti-consumption among young people?

In the following, a short literature review introduces a theoretical foundation to the role of anti-consumption among young people. The qualitative approach is further described in the methodology section. Subsequently, findings of the study are presented and discussed. Implications for policy makers are then conveyed, limitations to the study disclosed, and avenues for further research are identified.

The study design allows us to identify motivational drivers behind reducing individual consumption. As expressed by Makri et al. (2020, p. 188), "it will be interesting to contrast the widely examined (explicit) drivers with inhibitors that operate more automatically and spontaneously" to close the current research gap. This study reflects broad, non-product-specific behaviour, as our study participants were not asked about their refraining from consuming products of specific categories such as food (Vantamay 2018) or fashion (Grauerholz and Bubriski-McKenzie 2012). Furthermore, the study does not focus on already committed anticonsumers specifically. Instead, it aspires to capture the perspective of a broader, more average consumer segment as potential target for enhancing anti-consumption in the population. While anti-consumption behaviour seems to contradict conventional marketing goals, understanding it is crucial for a transformation towards sustainable consumption and social well-being. Our research offers valuable insights and practical implications for researchers, policy makers, and activists who are interested in understanding anti-consumerist attitudes among young people and who aspire to prepare the future generation for living in a world presented with fundamental sustainability challenges. 


\section{Theoretical Foundations}

\section{Three Anti-Consumption Behaviours}

Anti-consumption scholars have focused on the reasons against consumption by studying the conscious and deliberate rejection, avoidance, reclaiming, and reduction of products, brands, and commercial transactions (Chatzidakis and Lee 2013; Lee et al. 2009). The broad and constantly developing research field covers a variety of practices, which range on a continuum of varying degrees of consumer involvement and consciousness (Guillard 2018; Makri et al. 2020).

Anti-consumption practices are often rooted in sustainability concerns (Seegebarth et al. 2016). Researchers have long theorized that anti-consumption may decrease waste and natural resource use (Black 2010) and lead to lessened ecological pressure (García-de-Frutos et al. 2018), a relation recently empirically confirmed by Kropfeld et al. (2018). Furthermore, overconsumption has been identified as a factor leading to low subjective well-being (Burroughs and Rindfleisch 2002) and reduced life satisfaction (Richins and Dawson 1992). Well-being and anti-consumption are positively associated (Lee and Ahn 2016), although the enforced reduction of consumption shows rather negative effects on personal satisfaction and happiness (McGouran and Prothero 2016).

Our research focuses on three materially reduced consumer behaviour patterns studied in relation to anti-consumption: voluntary simplicity, collaborative consumption, and living within one's financial means (Balderjahn et al. 2020). According to Balderjahn et al.'s (2013) comprehensive concept for consumers' sustainability consciousness, these three options reflect the conscious choice not to buy a product at all. Therefore, they overlap with anticonsumption, which deals with "reasons against" (stronger motivations to not consume) opposed to a lack of "reasons for" consuming (Chatzidakis and Lee 2013; Lee et al. 2009). The three options are explored in more detail below.

Motivated by non-materialistic values, voluntary simplifiers seek well-being and meaning through reduced levels of material consumption (Alexander and Ussher 2012; Ballantine and Creery 2010; Elgin and Mitchell 1977; Etzioni 1998; Shaw and Newholm 2002). This is associated with increased life satisfaction and lower environmental impact (Brown and Kasser 2005). Voluntary simplicity has been measured as a set of behaviours (Leonard-Barton 1981) and values or attitudes (Iwata 1997). Rich et al. (2020) developed the most recent scale for measuring voluntary simplicity based on the everyday life experiences of simplifiers. They consider material simplicity, a frugal approach to resources, local procurement, self-sufficient food production, giving back to the social community, and individually enacted work/life preferences. People who consciously consume less than they can afford make up a sixth of the German population, are prone to purchase few but preferably environmentally friendly products, and practice collaborative consumption (Peyer et al. 2017).

Collaborative consumption includes a wide range of activities. It allows access to goods that are either non-ownership-based through sharing, borrowing, or renting (Bardhi and Eckhardt 2012) or involves a transfer of ownership through swapping, gifting, or bartering (Belk 2014). The activity may take place between strangers or within social communities or commercial settings (Hawlitschek et al. 2018). Goods can be both tangible (e.g., cars, clothes, and furniture) or intangible (e.g., music and car rides) (Kim and Jin 2020). Collaborative consumption in the "sharing economy" continues to rise, especially in technology-supported commercialized settings (such as Airbnb and fashion rentals) (Hamari et al. 2016). 
Motivational reasons for this behaviour include the benefits of socializing, convenience through lessened responsibility, saving on personal costs, and protecting environmental resources (Belk 2014; Botsman and Rogers 2010; Möhlmann 2015; Mont 2004; Ozanne and Ballantine 2010). However, the sustainability effects of collaborative consumption are disputed. Some identify the practice as enabling additive consumption (Parguel et al. 2017). Others argue that the circulation of goods slows the production of new goods and decreases the need for raw materials (Botsman and Rogers 2010).

Living within one's means is associated with an avoidance of debt, attending to long-term financial security through consideration of budget constraints, and the accumulation of savings. This reflects the belief that purchase decisions should not exceed an individual's ability to meet present and future financial obligations, because a desire for long-term financial stability and a conscious sense of caring for one's long-term economic and personal well-being are part of a mindful balance which avoids both over- and under-consumption (Sheth et al. 2011). Economic aspects can be suspected to initiate conscious and deliberate decisions against product purchases. Furthermore, as "debt is usually incurred due to the desire or necessity to consume" (Balderjahn et al. 2020, p. 462), this option can be a valuable part in anticonsumption research. However, these aspects have been explored in only a few studies so far. Some focus on individual-level motivators for anti-consumption like saving money (Elgin and Mitchell 2003; Black and Cherrier 2010) and avoiding debt (Balderjahn et al. 2020; Nepomuceno and Laroche 2015). Research revealed that frugal consumers tend to have higher account balances and voluntary simplifiers are less likely to have personal debts than consumers with more materialistic concerns (Nepomuceno and Laroche 2015). Repetitive excessive purchasing threatens consumers' individual well-being (Brown and Gray 2016; Sweet et al. 2013) and is associated with negative environmental and social consequences (Cohen 2007).

Our coverage builds on a recently provided definition of anti-consumption as "intentionally and meaningfully excluding or cutting goods from one's consumption routine or reusing onceacquired goods with the goal of avoiding consumption" (Makri et al. 2020, p. 178). This definition presupposes that consumers act intentionally and that their actions hold meaning for them. Voluntary simplicity clearly fits this definition as does collaborative consumption. Borrowing or renting a product does avoid purchasing and subsequent private ownership. It also corresponds with reusing of once acquired goods, as goods are used by several people and not just by the buyer. This prolonging of product lifecycles was also identified as a promising research endeavour for anti-consumption in the post-consumption stage (Makri et al. 2020). Living within one's means indicates a conscious avoidance of consumption, as individuals consciously decide to avoid debts and not to exceed their financial endowments for consumption. All three options are therefore considered in this work to explore their role in motivating or constraining young people's anti-consumption.

\section{Sustainable Anti-Consumption Among Young People}

\section{Age of Transition}

In the transitional phase between childhood and adulthood, young people are a diverse and ambiguous consumer group with studies revealing rather incongruous characterizations. Research addressing this age group (roughly 14 to 24 years) uses a variety of interchangeable 
defining terms, including young adults (Cloutier and Roy 2020; Kemp et al. 2020; Kreuzer et al. 2019; Shim et al. 2015), youth (Amin et al. 2018; Goldberg et al. 2003; Slater et al. 2018), adolescents (Effertz et al. 2014), and young people (Calafell et al. 2019; Te'eni-Harari 2014; Wilska 2003).

Almost from birth, individuals are targeted as consumers by marketing and policy making (Mau et al. 2014; Schor 2004). As a much sought-after market segment highly exposed to the persuasions of marketing and lifestyle appeals, young people may be a vulnerable consumer group due to their usually lower incomes and lack of experience in the consumer market (Luukkanen and Uusitalo 2019). They also develop new attitudes and cognitive and social skills as increasingly independent consumers in the marketplace (Ward 1974). However, young consumers' autonomy in the developmental process depends heavily on their family structures, specific living conditions, and cultural contexts. Research has identified different developmental stages of consumer socialization. John (1999) defines the earlier age span from 11 to 16 as the reflective stage. In this stage of adolescence, teenagers become increasingly sceptical of advertising, begin to understand, and value the symbolic meanings of brands for group identities, use sophisticated product information search strategies, strategically influence parental decisions through persuasion and bargaining, and grow susceptible to materialistic values. Arnett (2000) identifies emerging adulthood (roughly the ages of 18 to 25) as a separate period of life between adolescence and adulthood in industrialized countries. Emerging adults are challenged in their consumer roles, as this transitional period is marked by engaging in different activities, gradually accepting responsibility for oneself, making independent decisions, and becoming financially independent before settling into long-term adult roles. Kreuzer et al. (2019) also identify housekeeping, time management, and building relationships in the private and work spheres as common life challenges of this age span.

\section{Young People as Anti-Consumers}

In these developmental stages, young people develop values that may influence their behaviours as adult consumers, giving them the opportunity to positively influence their future (de Araujo Gil et al. 2016). However, current risks of young people reaching unsustainable overconsumption are high in industrialized countries (Fischer et al. 2017). Especially in stages characterized by high levels of personal insecurity such as puberty, consuming marketed goods not only serves the purpose of satisfying basic needs (Joyner Armstrong et al. 2016) but also creates identity and social status (Belk 1988), triggers peer pressure (Goldberg et al. 2003), serves as leisure activity, and may result in dysfunctional compulsive buying behaviour (Dittmar 2005).

Only a limited number of studies have focused on anti-consumer behaviours and attitudes in this age group so far. Teenagers' resistance to consumption acts has been explored in studies on those who reject attending the ritualized event of the high school prom (Tinson et al. 2013; Tinson and Nuttall 2011) and on African American girls who disapprove of Eurocentric female beauty norms encouraged by popular teen magazines (Duke 2002). These examples of resistance behaviours are rather specific and are not generalizable to anti-consumption attitudes or behaviours with a sustainability background. Furthermore, young people have primarily been in the spotlight of anti-consumption research through student samples covering, for instance, issues of politically motivated anti-consumption (de Barcellos et al. 2014), alcohol resistance (Piacentini and Banister 2009), responses to corporate boycotts (Yuksel and Mryteza 2009), social-psychological bases of anti-consumption attitudes (Zavestoski 
2002), and connections between resistance to consumption and materialism (Nepomuceno and Laroche 2017).

Concerning the three dimensions of anti-consumption covered in this study, researchers have identified several major psychological obstacles that prevent teenagers from positively engaging in voluntary simplicity and from living within their financial means. Both frugality and generosity decrease as children grow older, leading to the assertion that teenagers adopt materialistic values in consumerist cultures (Kasser 2005). Dittmar (2005) found teenagers (16-18 years old) to be more prone to compulsive buying than adults. Young consumers who report high levels of materialism, but low degrees of generosity and frugality, exhibit lower self-esteem (Chaplin and John 2007). They are less likely to engage in resource-saving behaviours such as bicycling, conserving electricity, or recycling materials (Kasser 2005). Nevertheless, in a study focusing on food and clothing, Kreuzer et al. (2019) found that while product prices constitute the decisive aspect of a purchasing decision, young Germans realize sustainable consumption through buying something only when truly needed, as well as through donating discarded goods to others.

Family socialization is an important factor in this context because within families, parents' environmental orientation tends to transfer to the children (Grønhøj and Thøgersen 2012; Matthies and Wallis 2015). Generally, adolescents are found to be less environmentally committed than their parents in their values as well as their attitudes towards and performance of energy saving, waste separation, and purchasing of environmentally friendly goods (Grønhøj and Thøgersen 2009). Despite such behaviours, findings on value development through life stages (Goodwin et al. 2012) suggest that adolescents' environmental values can be expected to increase with maturity when such values were exemplified in their family home (Grønhøj and Thøgersen 2009). Furthermore, after an educational intervention, children were found to be able to positively influence parents' concern about climate change (Lawson et al. 2019).

Concerning living within one's means, increasing rates of over-indebtedness among young people threaten their financial stability, health, and psychological well-being (Elliot and Lindblom 2019; Tran et al. 2018). Borrowing money to purchase consumer goods has recently been triggered by new markets and social media use (Sotiropoulos and d'Astous 2012) as well as peer influences (Sotiropoulos and d'Astous 2013), low financial involvement, and presentbiased temporal discounting (Gärling et al. 2020). Parental influence is the most important factor that affects children's saving and spending behaviours, shaping their lifelong financial patterns (Bucciol and Veronesi 2014; Shim et al. 2010; Webley and Nyhus 2013). To balance variations in economic socialization by parents, living within one's means has received increased attention in educational research and school curricula since the financial crisis of 2008 (Frühauf and Retzmann 2016).

Young consumers are more inclined towards collaborative consumption modalities than older consumers (Lindblom and Lindblom 2017). Possible reasons for this include the use of modern technological appliances, lower incomes, and a greater awareness of environmental issues (Bardhi and Eckhardt 2012; Möhlmann 2015; Rudmin 2016). Collaborative consumption, therefore, may help draw young consumers towards patterns of moderate consumption.

To summarize, the literature reveals ambiguous characterizations of young people as potentially sustainable anti-consumers. On the one hand, young people use the tools provided by consumer society to establish their identities while questioning previously learned values and behaviours. On the other hand, they may generate an awareness of the more critical aspects of a mass consumption society. The latter aspect inspires our research on young people's motivations to engage in anti-consumption. 


\section{Method}

\section{Approach}

In this study, we make use of means-end chain theory. According to Gutman (1982), consumers evaluate alternatives of a choice set (means) based on anticipated consequences that derive their meaning from the degree to which they satisfy superior values (ends). In using this well-established approach to identify cognitive motivations guiding a consumer's decision to spend or save, the present study adopts the means-end chain (MEC) framework developed by Olson and Reynolds (1983). The framework distinguishes between the following elements (in ascending order): attributes of alternatives within a choice set (e.g., products, people, behaviours), the functional and psychosocial consequences of such attributes, and the connected instrumental and terminal values to which people aspire.

In our study design, we rely on three types of anti-consumption behaviour which represent the attribute level of MEC analysis, namely voluntary simplicity (buying only goods one actually needs, abbreviated as simplicity for readability in the following), collaborative consumption (borrowing items instead of purchasing them) and living within one's means (avoiding non-affordable purchases). Functional and psychosocial consequences are the perceived benefits and costs that consumers associate with certain attributes. Values are defined as the "criteria people use to select and justify actions and to evaluate people (including the self) and events" (Schwartz 1992, p. 1). Values complete the chain as the superior goals of nonconsuming activities.

Although MECs are traditionally initiated with tangible attributes of material goods in the context of product development and evaluation (Reynolds and Phillips 2009), the approach is suitable for studying any kind of decision-making process (e.g., regarding products, services, people, activities) about choice (Gutman 1982). For example, MECs have previously been successfully created for recycling choices (Bagozzi and Dabholkar 1994), household food waste avoidance (Richter and Bokelmann 2018), and car sharing usage motives (Schaefers 2013) before, thereby setting examples for our anti-consumption focus. We therefore continue to refer to the elements of the lowest stage of the MEC not as attributes but as behaviours to better frame their character as not related to a product.

To identify MEC relations, we use the well-established soft laddering interview technique (Grunert and Grunert 1995). The technique allows one to detect all MEC elements by continuously prompting the interviewee to verbalize his or her motivations by posing questions such as "Why does this matter to you?" or "Why is this important to you?" (Miles and Rowe 2004; Reynolds and Gutman 1988). Due the explorative nature of our study, the interviewers had to respond to the participants' statements in a flexible manner. The interviewers were allowed to provide thought-inducing prompts, which helped the interviewees express their motivations verbally, but the interviewers needed to avoid providing stimuli that would lead the interviewees in a specific direction. They were therefore extensively trained in the delivery of in-depth one-on-one interviews in a pre-study $(N=17)$, which also served to develop, test, and refine the interview guidelines.

\section{Sample}

Three trained interviewers conducted the interviews over a span of six weeks. The interviews took place at the central train station of a mid-sized city (170,000 inhabitants) in Germany. The 
public transportation hub, which is combined with a shopping centre, is an attractive meeting point for people of diverse backgrounds and motivations including tourists, commuters, shoppers, students, and teenagers. This setting allowed us to interview a broad range of young consumers, and therefore map the diverse perspectives existing towards anti-consumption. Without a binding age definition for the transitional phase between childhood and adulthood (Fien et al. 2008), we settled our sample of 55 young people aged 14-24 for theoretical and formal reasons. This age group also roughly reflects the United Nations' definition of "youth" and "young people" (ages 15-24). To ensure the best coverage of early consumer socialization stages, we also include those aged 14, which marks the earliest age people may be interviewed without the attendance of a parent or legal guardian in Germany. We set the age of 24 as a logical maximum age because most people will have finished or be in the final stages of their formal education at this age (school, university, or training school) and have reached a substantial degree of independence in their personal consumption. Using a convenience sampling approach (Robinson 2014), we still aimed for a rough sample stratification according to demographic control criteria which was achieved as shown by detailed statistics on our sample's demographics (Table 1). The sample was nearly completely balanced in terms of gender (27 females and 28 males) with a mean age of 18 .

\section{Procedure}

The interviews were only conducted after the anonymity, confidentiality, sources, and purpose of the data collection process were clarified. In compliance with common guidelines for surveying underaged persons (ESOMAR 2009), the teenagers also had to provide informed consent to participate in the interviews. In the first part of each interview, we measured the interviewees' understanding of voluntary simplicity, collaborative consumption, and living within one's financial means with a short 6-belief-item version (Table 2) of the Consciousness for Sustainable Consumption (CSC) scale (Balderjahn et al. 2013; Balderjahn et al. 2020). We then used the ratings for each behaviour on the CSC scale to mirror the attribute elicitation technique. In more traditional laddering contexts, this technique is applied to identify which attributes as characteristics of a product are salient in a participant's mind as a starting point for each laddering (Reynolds and Gutman 1988). Instead of eliciting product attributes, the CSC survey helped to identify the respondents' salience of each anti-consumption behaviour. For each behaviour with which the respondent agreed, the interviewer would then start the laddering process in the second part of each interview.

For instance, if a participant scored high on voluntary simplicity in the survey, the interviewer would start the laddering procedure with the question: "You stated that you prefer to buy a product only when it is useful and needed. Why is that important to you?" A response might be "I don't like clutter in my home." The interviewer would then proceed with "Why do you not like clutter at home?" to induce, for instance, the answer "I need my home to be clean, there should not be too much stuff that I don't use." The repetition of the inquiry "Why is this important to you?" allows a higher level of abstraction in the answers to each question, thereby revealing the consequences and values associated with the behaviour (e.g., voluntary simplicity in the example given above). During the interview, the interviewers took notes about the emerging ladders and read these to the participants afterwards to assure their correct understanding. After the laddering process, participants completed a short survey with demographic questions. 
Table 1 Sociodemographic characteristics of the sample (14-24 years of age)

\begin{tabular}{|c|c|c|c|}
\hline Characteristic & Frequency & Percentage & Cumulative percentage \\
\hline \multicolumn{4}{|l|}{ Gender } \\
\hline Female & 27 & 49.1 & 49.1 \\
\hline Male & 28 & 50.9 & 100.0 \\
\hline \multicolumn{4}{|l|}{ Age } \\
\hline 14 & 9 & 16.4 & 16.4 \\
\hline 15 & 6 & 10.9 & 27.3 \\
\hline 16 & 4 & 7.3 & 34.5 \\
\hline 17 & 8 & 14.5 & 49.1 \\
\hline 18 & 6 & 10.9 & 60.0 \\
\hline 19 & 1 & 1.8 & 61.8 \\
\hline 20 & 5 & 9.1 & 70.9 \\
\hline 21 & 4 & 7.3 & 78.2 \\
\hline 22 & 7 & 12.7 & 90.9 \\
\hline 23 & 3 & 5.5 & 96.4 \\
\hline 24 & 2 & 3.6 & 100.0 \\
\hline \multicolumn{4}{|l|}{ Household size (members) } \\
\hline 1 & 6 & 10.9 & 10.9 \\
\hline 2 & 12 & 21.8 & 32.7 \\
\hline 3 & 17 & 30.9 & 63.6 \\
\hline$\geq 4$ & 20 & 36.4 & 100.0 \\
\hline \multicolumn{4}{|l|}{ Highest educational level } \\
\hline None & 20 & 36.4 & 36.4 \\
\hline Lower secondary school & 2 & 3.6 & 40.0 \\
\hline Secondary school & 15 & 27.3 & 67.3 \\
\hline High school & 18 & 32.7 & 100.0 \\
\hline \multicolumn{4}{|l|}{ Employment status } \\
\hline Full-time & 7 & 12.7 & 12.7 \\
\hline Part-time & 8 & 14.5 & 27.2 \\
\hline None & 38 & 69.1 & 96.3 \\
\hline Missing & 2 & & \\
\hline
\end{tabular}

Table 2 Questionnaire on the consciousness for voluntary simplicity, collaborative consumption, and living within one's financial means according to the Consciousness for Sustainable Consumption scale (Balderjahn et al. 2013; adapted wording obtained from Balderjahn et al. 2020)

\begin{tabular}{|c|c|c|c|c|}
\hline $\begin{array}{l}\text { Strongly } \\
\text { disagree }\end{array}$ & Disagree & $\begin{array}{l}\text { Neither } \\
\text { agree } \\
\text { nor } \\
\text { disagree }\end{array}$ & Agree & $\begin{array}{l}\text { Strongly } \\
\text { agree }\end{array}$ \\
\hline
\end{tabular}

Even if I can financially afford a product,

I will buy it only if...

Voluntary simplicity

... I really need the product.

$\ldots$ it is a useful product for me.

$\mathrm{O}$

$\mathrm{O}$

$\mathrm{O}$

$\mathrm{O} \quad \mathrm{O}$

Living within one's means

... my expenses are not an excessive financial burden for $\mathrm{O}$

O

$\mathrm{O}$

$\mathrm{O}$

$\mathrm{O} \quad \mathrm{O}$

me.

... I do not have to cut down on future spending.

$\mathrm{O} \quad \mathrm{O}$

$\mathrm{O} \quad \mathrm{O}$

Even if I can financially afford a product,

$\begin{array}{lllll}\mathrm{O} & \mathrm{O} & \mathrm{O} & \mathrm{O}\end{array}$

I tend to...

Collaborative consumption

... borrow products from friends or acquaintances instead $\mathrm{O}$ of buying it.

... share products with others instead of owning it myself. O

$\begin{array}{llll}\mathrm{O} & \mathrm{O} & \mathrm{O} & \mathrm{O} \\ \mathrm{O} & \mathrm{O} & \mathrm{O} & \mathrm{O}\end{array}$




\section{Analysis}

Two researchers performed iterative coding (Grunert and Grunert 1995) of the collected data. They deliberated on their independently obtained results over several rounds of discussion to clarify disagreements. The final code system includes the three anti-consumption options representing behaviour codes, nine codes for functional consequences, seven codes for psychosocial consequences, four for instrumental values, and seven for terminal values (Table 3). In total, 80 of 197 ladders (40.6\%) reached the highest level of abstraction, identifying them as instrumental or terminal values.

Manually constructed hierarchical value maps (HVMs) provide a graphical representation of the dominant code relations. The HVMs depict the central linkages across MEC elements that exceed a pre-defined cut-off level of three, which ensures a sufficient representation of the structures' complexity while providing a clear arrangement of our data. The maps include direct and indirect relationships (Miles and Rowe 2004). HVMs are calculated based on an implication matrix, which is a summary table displaying all pairwise summarized code relations in the data with direct relations shown to the left of the decimal and indirect relations shown to the right of the decimal (Reynolds and Gutman 1988). Table 3 displays a joint implication matrix for the three anti-consumption options. Taking the connections between voluntary simplicity and "avoid wasting money" (code no.2) for example, the value 15.2 in their intersection cell means there are 15 direct and 2 indirect connections. The implication matrix also tells that these two indirect connections are connected via "avoid wasting space," due to the value 2.0 in the intersection of codes no. 1 and no. 2 in the implication matrix.

Figure 1 shows the anti-consumption HVM for young people for simplicity, and Figures 2 and 3 show the same data for living within one's means and collaborative consumption. Active codes are arranged by level of abstractness with the respective behaviours shown at the bottom and the terminal values shown at the top. Numbers shown along the lines denote the number of links between each code. When connections between two codes are exclusively indirect, lines are dashed (e.g., seven indirect connections between "voluntary simplicity" and "intellectual growth" as the value 0.7 in the intersection of voluntary simplicity and code no. 23 in the implication matrix implicates). Direct and indirect connections between codes are summed up and denoted by continuous lines (e.g., the value 17 as sum of 15 direct and 2 indirect connections labels the continuous line between "voluntary simplicity" and "avoid wasting money" in the respective HVM).

\section{Findings}

When comparing the three HVMs for anti-consumption options, "save money" emerged as a dominant functional consequence with 63 mentions across all maps. Saving money is directly related to the value "security" for collaborative consumption while connections to "social experiences" and "well-being \& happiness" occur for simplicity. Some interviewees explained that they prefer to save money to spend on joint experiences with friends rather than on more goods.

"Saving money" conceptually differs from "avoid wasting money," which is another code occurring 33 times across all three HVMs. Saving money implies saving for a special purpose while the avoidance of wasting money was mostly treated as an end in itself. For collaborative 


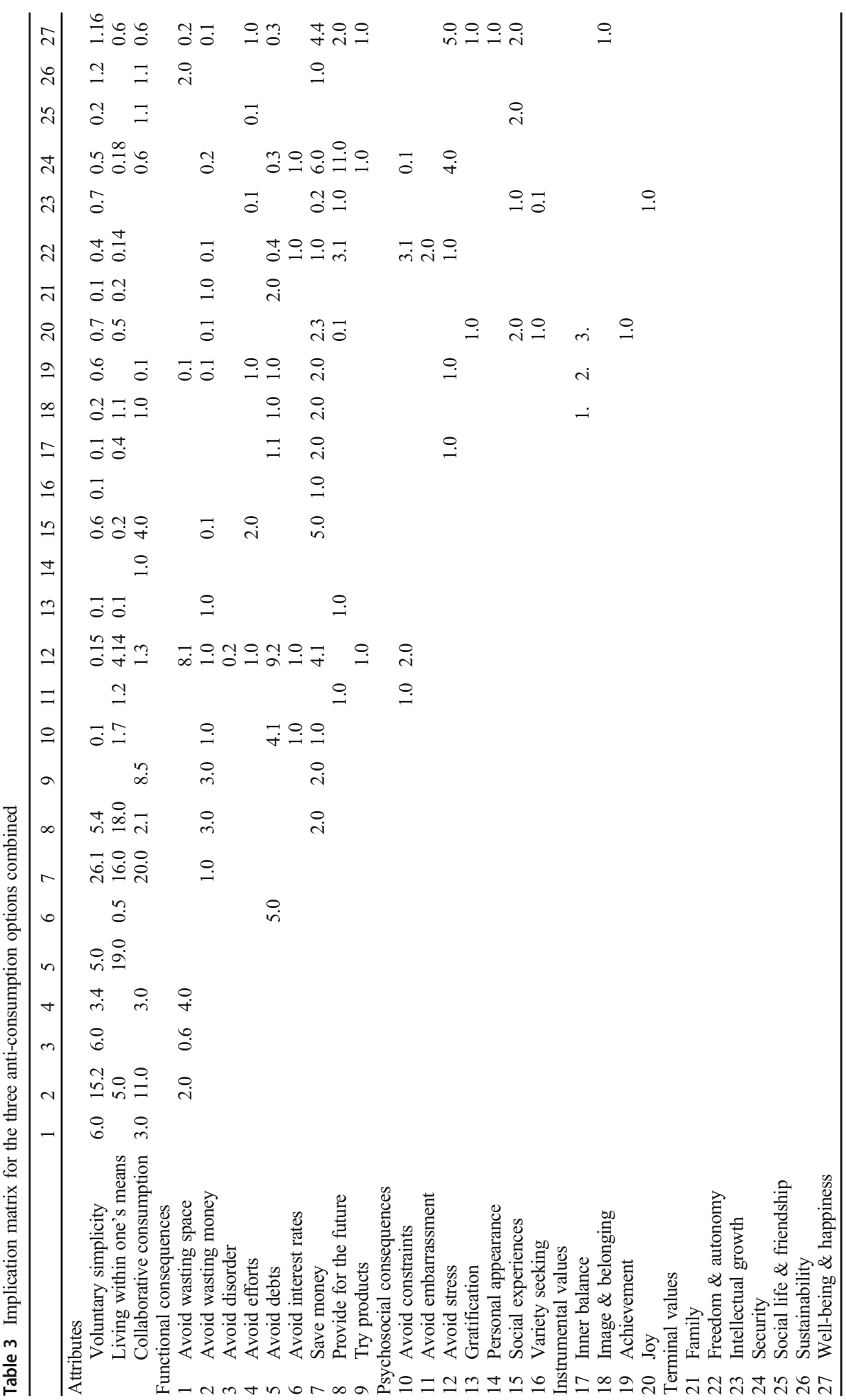


consumption, an important motivation to borrow products rather than buying them was found to be the intention to try out different products instead of owning a particular product, mediated by "avoid wasting money" in three cases.

As the demographic structure of our sample indicates, most of our interviewees are still in school, not (yet) employed, and live with at least two more household members. Thus, the HVMs represent the perspectives of individuals who do not yet earn and manage their income independently but rely on household income. Therefore, we assume that the financial resources of our sample are rather limited. Nevertheless, the young people are looking ahead in caring about their financial well-being as the code "provide for the future" shared by all three maps indicates. For living within the means, "avoid debts" leads to "provide for the future," which directly leads to the value "security." "Avoid stress" is also preceded by "avoid debts" and leads to "security" while "avoid constraints" as a consequence of "avoid debts" leads to the value "freedom and autonomy." Although the interviewees, due to their age and living conditions, still have rather limited individual responsibility over their income and financial maintenance compared to older people, they already express concern for their future financial stability. This seems to be connected to a long-term desire for freedom and autonomy. "Freedom and autonomy" is a rather prominent code for living within one's means, but it is only indirectly connected via different functional consequences.

Simplicity and collaborative consumption share the consequence "avoid wasting space." In the simplicity map, this results from "avoiding disorder" due to owning too much stuff. Here, the interviewees also relate wasting space to necessitating extra effort (tidying up or needing additional furniture) and experiencing stress. While not related to wasting space, avoiding effort and stress also motivate collaborative consumption.

Collaborative consumption is also motivated by "social experiences," because it causes individuals to get together to share and use goods. "Gain access to products," another consequence of collaborative consumption, implies that young people share rare or expensive goods as well. While access to goods through sharing might be interpreted as an equalizing process between unevenly endowed consumer groups, it may also cause an additive consumption of unnecessary products and an increased use of resources.

Although rather indirectly and not in all cases exceeding the cut-off level, young people noticeably associate "well-being \& happiness" with saving money and avoiding stress. Connections between "well-being \& happiness" and psychosocial consequences such as "social experiences," "personal appearance," or "gratification" remain as exceptions. The same applies to the values "joy," "achievement," and "intellectual growth," which are included in the simplicity map through indirect relations. Nevertheless, the terminal value "well-being and happiness" occurs in all three HVMs. It represents a relevant motivation for the practice of anti-consumption among young people, although through ambiguous motivations.

The maps display existing motivations, but they also reveal which codes do not appear in the ladders. Of the 27 detected codes for functional consequences, psychosocial consequences, instrumental values, and terminal values, 18 remain represented in the HVMs. Although the studied anti-consumption behaviours have a strong conceptual relation to sustainability, sustainability was not prevalent in the cognitive structures of the young sample. The number of mentions of possible other anti-consumption motivations like family and justice did also not exceed the cut-off level in the HVMs. Furthermore, the analysis shows few complete ladders covering all MEC elements, suggesting that the studied age group experienced difficulty expressing their motivations in this structured manner. 


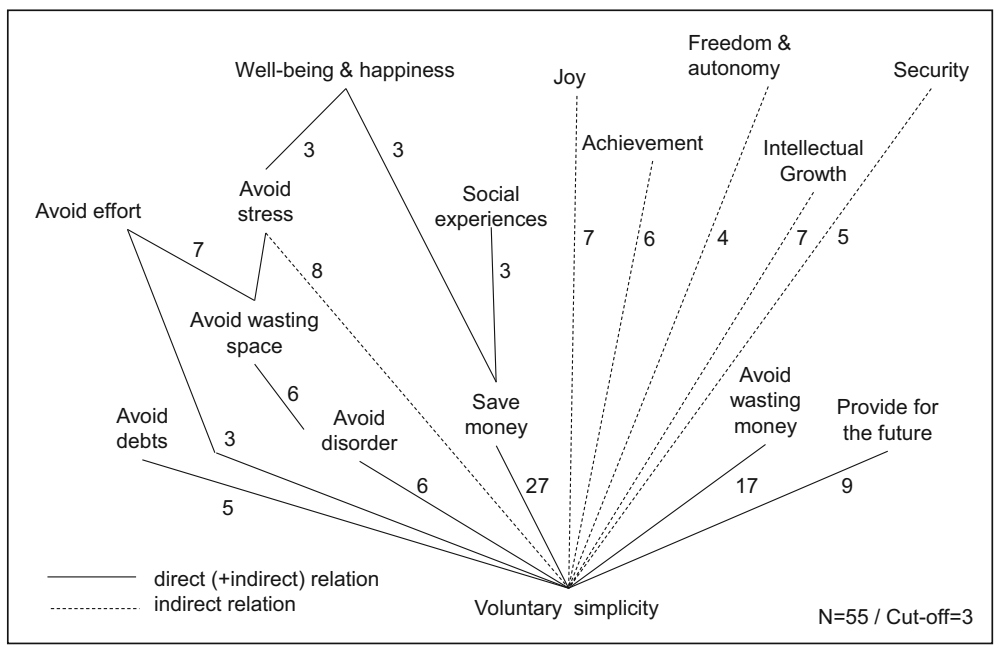

Fig. 1 Hierarchical value map for voluntary simplicity

\section{Discussion}

The composition of the HVMs allows us to draw conclusions about young people's motivations behind practising anti-consumption. Knowledge about these motivations may help to successfully engage young people in its related activities, which ultimately helps to moderate consumption levels.

First, the dominance of "save money" and "avoid wasting money" suggests that financial factors are a prominent issue for young people's engagement with anti-consumption. Consumers have the option to stress their financial resources for purchases, for instance through

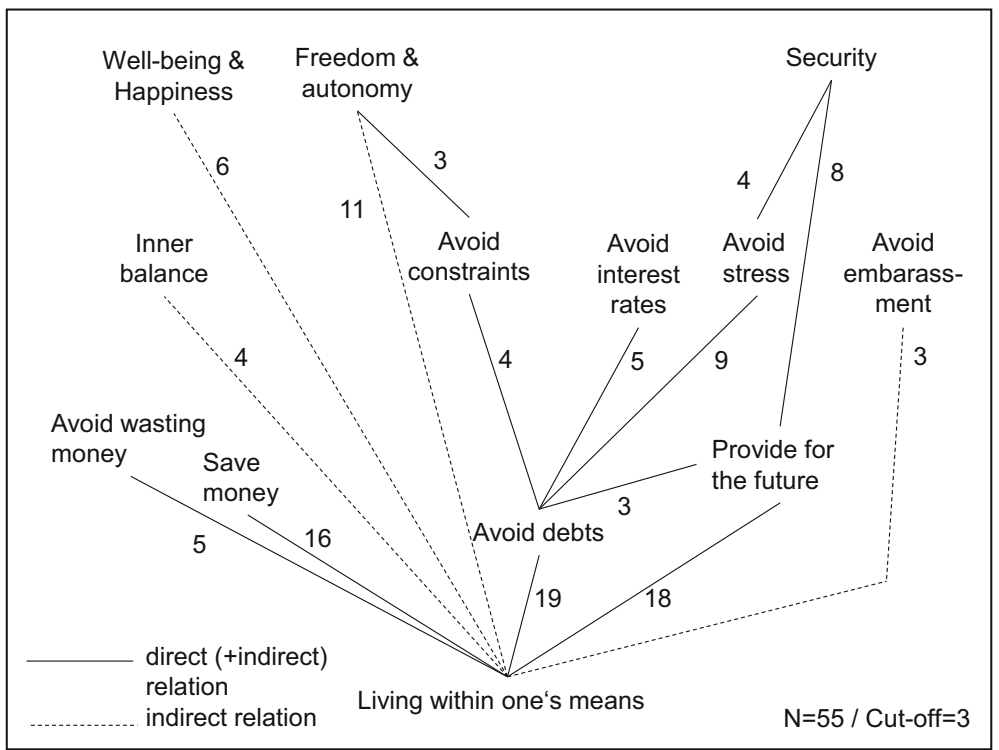

Fig. 2 Hierarchical value map for living within one's means 


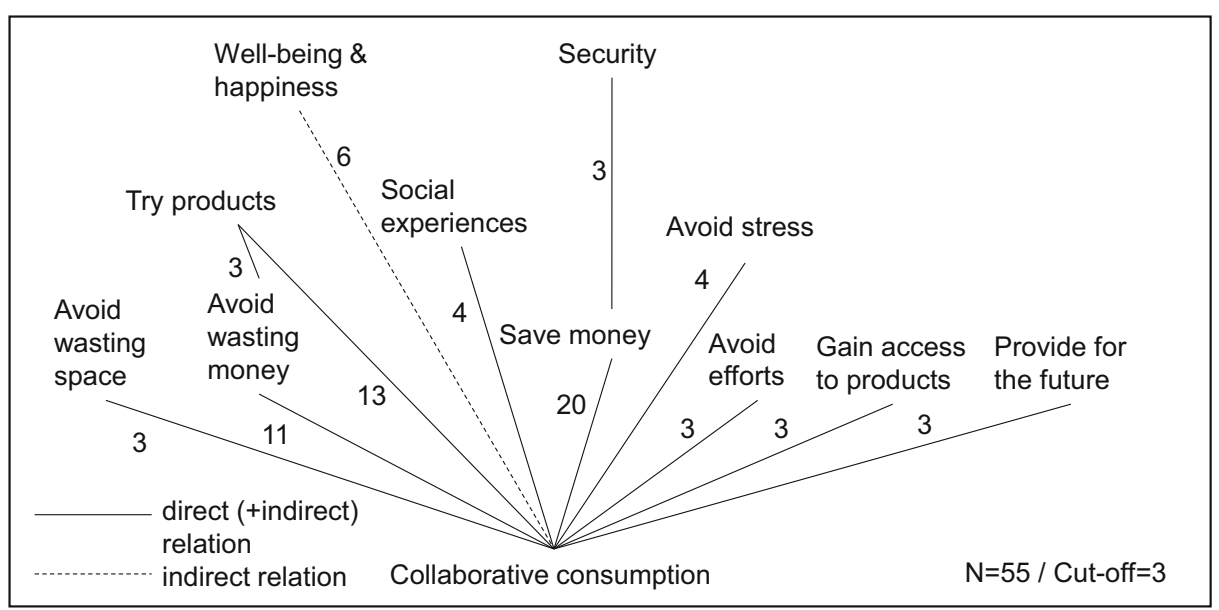

Fig. 3 Hierarchical value map for collaborative consumption

easily available consumer credits or private loans (Cloutier and Roy 2020). Recent research has found that consumer credit and debts are normalized among young adults (Hohnen et al. 2020). Interestingly, the young interviewees in our sample express little interest in exceeding their financial means, which allows the interpretation of "living within the means" as voluntary choice and motivation to consume less. Responsibly dealing with financial resources to achieve greater ends might therefore serve as a gateway to activate young people's motivation to actively forego unnecessary purchases and hold their personal consumption at a moderate level over the long run. As "freedom and autonomy" is a prevalent value in the simplicity and living within the means maps, the motivation to remain financially independent to allow for a self-determined lifestyle constitutes a promising avenue for anti-consumption communication. These motivational structures behind anti-consumption also offer a logical inclusion of sustainability themes. Sustainable behaviour aims at securing living standards over the long term. For young people who are already aware of the need to control their expenses for the sake of their individual long-term well-being, moderating their consumption levels for the sake of securing stable living standards and thus ultimately protecting their freedom of choice should be a plausible matter. Additionally, consumer goods with an environmental or social benefit often come with higher purchase costs. High prices, as well as behavioural costs, are a central barrier to sustainable consumption among young adults even though their intentions to behave sustainably are already developed (Kreuzer et al. 2019). Anti-consumption breaks this central barrier, because its practice embodies the opposite of purchasing costlier and a higher number of goods. It furthermore does not require access to specific sustainability-focused retail places (Joyner Armstrong et al. 2016). While voluntary simplicity and collaborative consumption have been used to measure sustainability-related anti-consumption before (Seegebarth et al. 2016), living within one's means has largely been out of the picture. Nevertheless, our combination of the three behaviours generates HVMs that show what these three dimensions have in common. They share saving money as well as the avoidance of wasting money as central financial motivations, which are perceived as paths towards living by positive terminal values such as well-being and security in life.

Second, some adolescents stated that they prefer spending their money on experiences with friends instead of on products. This is a positive notion because research has found no 
evidence that early adolescents' well-being profits from owning large amounts of goods (Sweeting et al. 2012). Furthermore, experiences may be less resource-intensive than goods and lead to more sustained feelings of happiness than material purchases (Kumar and Gilovich 2015). However, young people are aware that experiences are not necessarily free and require spending, for instance for travel, tickets, etc. (Grauerholz and Bubriski-McKenzie 2012; Tinson et al. 2013). Policy-supported infrastructures and social marketers might adjust to encourage young people to participate or even arrange shared experiences that do not require much financial and environmental resource, but that enhance individual and social well-being.

Third, according to our findings, young people rarely connect anti-consumption practices with sustainability values. This observation supports existing research which identifies the phase of adolescence as somewhat pro-consumption oriented (Kalmus et al. 2009) and low in sustainability consciousness (Olsson et al. 2016). Nevertheless, such research mostly focuses on Generation Y members born between 1978 and 1994 (Hume 2010; Stanes et al. 2015). Our study includes members of the succeeding Generation $\mathrm{Z}$ as an important research contribution. Scholarly perspectives on young consumers require regular updates because consumer behaviour does not change consistently with age but nonetheless is affected by generational influences. Sustainability consciousness tends to be lower among young consumers than adults (Hume 2010; Stanes et al. 2015) but may grow stronger with increasing age (Grønhøj and Thøgersen 2009). It thus appears even more important to establish sustainable consumption practices and patterns as routines among that age group (Fischer et al. 2017), especially as they are about to form their own households (Stanes et al. 2015). Furthermore, although environmentally friendly activities among young consumers have been the focus of various studies, including the purchase of green products (Pham et al. 2019), recycling (Ojala 2008; Schill et al. 2020), or the use of second-hand clothing (Xu et al. 2014), the anti-consumption behaviours covered in our study have largely remained unexamined to date. The behaviours originate from research on sustainable consumption (Balderjahn et al. 2013) and are highly relevant for reducing the environmental impact of overconsumption (Balderjahn et al. 2020). Therefore, sustainability remains a potential positive side effect of anti-consumption. Our research revealed financial benefits, social experiences, and stress avoidance as motivations to reduce material levels of consumption. To strengthen anti-consumption as a common individual practice for sustainable development, not necessarily sustainability, but these divergent motivations could be emphasized as motivations. Kreuzer et al. (2019) identify a lack of knowledge, doubts about one's own influence on climate change, and a lack of time to gather information as barriers to closing young adults' intention-behaviour gap concerning sustainable consumption. These barriers may be addressed through the adoption of empowering tools of consumer policy (Thøgersen 2005), which are proposed in the following. Research found that people who believe in significant positive sustainability effects of their consumption choices are more likely to behave in a sustainable manner (Antonetti and Maklan 2014; Leary et al. 2014). We therefore focus on education and communication as tools with an elucidative function, which were also suggested to strengthen sustainable consumer behaviour before (Hume 2010; Kadic-Maglajlic et al. 2019; Thøgersen and Schrader 2012).

\section{Implications}

In the following, our findings are related to two empowering governance scopes suitable for consumer policy: (a) education, and (b) communication. 
(a) Education: The age group explored in this research is likely to still participate in the education system. For them, consuming is an important aspect of identity creation (Kadic-Maglajlic et al. 2019) that our HVMs illustrate to be motivated largely through individual benefits. Educational materials and teaching methods must reflect students' everyday lives and personal value orientations (Hüttel et al. 2020). To appeal to prevalent interests such as smart financial behaviour, education about anti-consumption should highlight personal benefits instead of altruistic motivations. One possibility is to consider students' financial constraints as reflected by living within their means. Another, potentially complementary approach is the use of emotionalizing, interactive methods, which enable young people to reflect on the nonmaterialistic values of security, social belonging, and well-being. Such thinking about what constitutes a good life triggers positive emotion that improves learners' cognitive performance (Gläser-Zikuda et al. 2005). Furthermore, a holistic pedagogy involving cognitive as well as emotional and physical learning allows more effective transformative environmental education for sustainable behaviour changes (Judson 2015; Montiel et al. 2018; Shrivastava 2010). Appropriate methods might involve the use of news as teaching cases to elicit emotions according to a literary-genre-based framework (Montiel et al. 2018) or engaging students as critical agents with real problems in a participatory way (Räthzel and Uzzell 2009). If an individual develops consciousness of the individual, social, and environmental benefits of anti-consumption, no additional funds, special knowledge about products, or access to retailers should be required to actively forego purchases. Furthermore, alternative consumption practices and social innovations such as do-it-yourself practices, upcycling, or sharing may gain attractiveness (Jaeger-Erben et al. 2015). Innovative practice-oriented approaches to raising awareness of sustainability issues in consumption have been positively reviewed before (McEachern et al. 2020). Physical hands-on experiences as part of education gained through sharing goods, recycling project workshops, or working in community gardens help students to understand the value of the resources they use on a daily basis and to teach skills such as handcrafting.

While some people may already practice anti-consumption, scaling its impact is an important means of gaining support for the diffusion of anti-consumption through policy processes. Education is not a singular strategy but develops its full potential in coordination with governmental and economic activities that shape opportunities for individual action. Education represents a long-term investment in tackling pressing issues such as sustainability but also an investment that secures consumers' abilities and freedom to make independent and informed decisions without the need to exercise regulative measures.

(b) Communication: Despite the enormous harm caused by overconsumption, any research or policy addressing anti-consumption must respect the fundamental functions of consumption in human societies. Managing overconsumption through the absolute renunciation of goods and services appears to be unrealistic. In acknowledging the fundamental functions of consumption, for instance value satisfaction (Poças Ribeiro et al. 2019), effective communication on the issue should consider target groups' realistic ways to reduce consumption without compromising their definitions of a good life. After all, especially for young people, consumption is a way to construct their identity and manifest their belonging to a peer group while simultaneously expressing their individuality (Miles et al. 1998). 
Furthermore, consumption acts are not necessarily consciously reflected and freely chosen but are routines confined by material and social structures (Shove et al. 2012). Educational and communicative measures help consumers gain awareness about the unquestioned habits and structures that shape their decision making. "Freedom and autonomy" is an important value related to anti-consumption for young people. Therefore, sensitizing them about elements that subconsciously influence their preferences and confine their freedom of choice is a promising starting point for sparking critical reflection on the consumerist status quo. Additionally, as discussed above, communicating the effects of anti-consumption on financial independence should be attractive to young consumers who value their freedom and autonomy.

Beyond "freedom and autonomy," the interviewees associate several other positive consequences and personal values with the anti-consumption behaviours. These consequences and values can be positioned as direct or secondary benefits in a public discourse on reduced levels of consumption for sustainable development which fits the young generation specifically (Grønhøj and Thøgersen 2009). Anti-consumption must not necessarily be understood, promoted, or enforced as renunciative asceticism. Instead, voluntary anti-consumption options like foregoing unnecessary purchases, sharing goods, and staying within the financial budget encourage sustainability without threating people's needs while also providing various beneficial side effects (Defila and Di Giulio 2020).

The HVMs include a striking number of codes for the avoidance of a negative aspect (avoid wasting money, avoid disorder, avoid wasting space, avoid stress, etc.). This hints at anticonsumption being cognitively stored as a rather passive act to avoid negative consequences of consuming too much. This understanding might threaten its application, as avoiding something is less powerful for achieving a good quality of life than actively engaging to realize positive change. For effective communication, this means focusing on direct benefits and opportunities of engaging in anti-consumption. Especially for young people, the importance of communicating constructive hope has been highlighted in relation to environmental engagement before (Ojala 2012). The HVMs produced in our research therefore are valuable for constructing narratives based on young people's values which support their engagement with anticonsumption through storytelling (Fischer et al. 2020; Howarth 2017; Veland et al. 2018).

\section{Limitations and Further Research}

Considering the complexities of anti-consumption, we focused on three relevant options for young consumers: voluntary simplicity, collaborative consumption, and living within one's financial means. These three options do not allow us to completely capture the diverse activities studied in the body of anti-consumption research. For instance, consumer boycotts, boycotts, and direct purchases from producers as anti-consumption acts for environmental protection and social justice were out of the scope of this study (Hutter and Hoffmann 2013; Makarem and Jae 2016). Nevertheless, our focus enables us to identify interesting relationships between these anti-consumption options. They also offer a perspective closely reflective of the realities of teenagers' everyday lives.

We adopted a qualitative research approach to better understand young people as a rather new target group for anti-consumption studies. Adolescents and young adults form a population segment that is difficult to assess. We conducted a satisfying number of laddering interviews $(n=55)$ to perform a means-end chain analysis, and we recruited our interviewees 
in a public space attractive to teenagers of diverse social backgrounds. However, this study was still conducted on a specific target group. Conducting our study in Germany, one of the most economically developed countries in the world with an affluent Western consumer culture context, limits the scope of our research to rather privileged consumer groups. Examining the consumption levels of less affluent groups will require a reframing of anticonsumption within sufficiency (Gorge et al. 2015), which must be discussed elsewhere. While laddering is a sophisticated method for eliciting cognitive structures, affective aspects ultimately influence any consumer decision in real life situations and there are limitations to the universal applicability of the consumer-identified elements explored in laddering interviews. To ensure high intercoder reliability, the coders rigorously discussed and, where necessary, revised their coding decisions to achieve a precise coding framework. As a result, the interviews afforded deep insights within the scope of our research.

According to our findings, sustainability is a rather minor motivating value for young people. To strengthen the potential of anti-consumption within the pursuit of sustainable development, relating research findings about education for sustainable development with those on anti-consumption might allow both disciplines to benefit from each other in "planting the seed" for more environmental awareness. Education is not a singular strategy but develops its full potential in coordination with governmental and economic activities that shape opportunities for individual action. In this way, a global youth movement such as Fridays for Future would have been hardly imaginable without the activating and organizational influence of technology and social media in particular. In the opportunities and threats of new digital appliances for reduced levels of consumption lie promising avenues for future research. While a clear action plan for reducing negative impacts consumption patterns through consumer policy is important and desirable, more research on the young target group and the conditions shaping its decisions for and against the use and purchase of goods is required to inform such a plan. For instance, research on intragenerational transmission of anticonsumption orientations between parents and children might be of use.

Although the laddering interviews focused on young people's perspectives as individual consumers, the responsibility to achieve sustainable consumption cannot be assigned to individuals alone but must be acknowledged as a collaborative act (Fuchs et al. 2016; Thøgersen 2005). Public infrastructures are known to benefit alternative consumption and production practices, which support sustainable anti-consumption through, for instance, publicly supported do-it-yourself and repair workshops (Jaeger-Erben et al. 2015; Ziesemer et al. 2019). Therefore, the infrastructures that shape everyday consumer behaviours should be considered for policies as well. While our study design focuses on the selection, acquisition, and use stages of products, consumption involves further goods such as services and infrastructures, as well as the selection, storage, disposal, and reprocessing of goods. Future research might further elucidate the potential of such public infrastructure to engage young anti-consumers, specifically in the different stages of consumption.

Furthermore, people who voluntarily reduce their individual consumption experience obstacles such as a lack of product information or suitable employment for their lifestyle (Alexander and Ussher 2012; Ziesemer et al. 2019). Consumer policy initiatives may help address these obstacles (Rich et al. 2020). Additionally, sustainable and just economic structures must allow for the satisfaction of essential needs for all without limiting the freedom to access the means necessary to lead a good life (Soper 2007). These difficult, often normative discussions might profit from further research. For instance, for consumers who are used to easily satisfying their spontaneous desires, nudging may be a viable option (Sunstein and 
Reisch 2019). Nudges could be designed to inspire consumers to reconsider whether they truly need a product before buying it. Such approaches may prevent consumers from overconsuming goods that do not necessarily enhance their well-being while protecting their individual freedom of choice.

A growing body of research studies are confirming the relations between anti-consumption patterns and increased personal well-being (Hüttel et al. 2020; Lee and Ahn 2016; Seegebarth et al. 2016). Further findings in this direction might support the implementation of anticonsumption in broader contexts, as well-being is a universal goal of consumer policy (Mathios et al. 2020). Nevertheless, additional research is needed regarding the causes, development, and effects of anti- and pro-consumption as conflicting motivational paths to personal well-being.

\section{Conclusion}

Based on laddering interviews held with individuals of 14 to 24 years of age and a subsequent means-end chain analysis, this paper presents motivations for anti-consumption among young people. The study results shed light on a consumer group that has so far received little attention in the anti-consumption discourse. Despite the relevance of reducing consumption for sustainable living, sustainability is identified as a minor motivation relative to personal benefits such as financial security and individual freedom and autonomy. Nevertheless, the analysis reveals opportunities to engage anti-consumption as a gateway to more sustainable consumption patterns. The task for consumer policy is to equip young consumers with the attitudes, knowledge, skills, and infrastructures to make consumption decisions best suited to their individual well-being while respecting their financial situations and environmental boundaries. While the international Fridays for Future movement continues to draw young people's attention to issues of environmental sustainability, motivations to reduce individual levels of consumption seem not to be strongly connected to sustainability concerns. However, anticonsumption practices may support environmentally compatible, socially just, and individually beneficial sustainable development. In utilizing such potential for sustainability and wellbeing, students, teachers, and policy makers must be involved in processes of systemic transformation.

Funding Open Access funding enabled and organized by Projekt DEAL.

Open Access This article is licensed under a Creative Commons Attribution 4.0 International License, which permits use, sharing, adaptation, distribution and reproduction in any medium or format, as long as you give appropriate credit to the original author(s) and the source, provide a link to the Creative Commons licence, and indicate if changes were made. The images or other third party material in this article are included in the article's Creative Commons licence, unless indicated otherwise in a credit line to the material. If material is not included in the article's Creative Commons licence and your intended use is not permitted by statutory regulation or exceeds the permitted use, you will need to obtain permission directly from the copyright holder. To view a copy of this licence, visit http://creativecommons.org/licenses/by/4.0/. 


\section{References}

Alexander, S., \& Ussher, S. (2012). The voluntary simplicity movement: A multi-national survey analysis in theoretical context. Journal of Consumer Culture, 12(1), 66-86.

Amin, S. A., Panzarella, C., Lehnerd, M., Cash, S. B., Economos, C. D., \& Sacheck, J. M. (2018). Identifying food literacy educational opportunities for youth. Health Education \& Behavior, 45(6), 918-925.

Antonetti, P., \& Maklan, S. (2014). Exploring postconsumption guilt and pride in the context of sustainability. Psychology \& Marketing, 31(9), 717-735.

Arnett, J. J. (2000). Emerging adulthood: A theory of development from the late teens through the twenties. American Psychologist, 55(5), 469-480.

Assadourian, E. (2010). Transforming cultures: From consumerism to sustainability. Journal of Macromarketing, 30(2), 186-191.

Aurifeille, J.-M., \& Florence, P. V. (1995). Determination of the dominant means-end chains: a constrained clustering approach. International Journal of Research in Marketing, 12, 267-278.

Bagozzi, R. P., \& Dabholkar, P. A. (1994). Consumer recycling goals and their effect on decisions to recycle: A means-end chain analysis. Psychology \& Marketing, 11(4), 313-340.

Balderjahn, I., \& Hüttel, A. (2019). Why consumers buy sustainably: The role of personal values. Marketing ZFP, 41(1), 24-38.

Balderjahn, I., Buerke, A., Kirchgeorg, M., Peyer, M., Seegebarth, B., \& Wiedmann, K.-P. (2013). Consciousness for sustainable consumption: Scale development and new insights in the esconomic dimension of consumers' sustainability. AMS Review, 3(4), 181-192.

Balderjahn, I., Lee, M. S. W., Seegebarth, B., \& Peyer, M. (2020). A sustainable pathway to consumer wellbeing: The role of anticonsumption and consumer empowerment. Journal of Consumer Affairs, 54(2), 456-488.

Ballantine, P. W., \& Creery, S. (2010). The consumption and disposition behaviour of voluntary simplifiers. Journal of Consumer Behaviour, 9(1), 45-56.

Bardhi, F., \& Eckhardt, G. M. (2012). Access-based consumption: The case of car sharing. Journal of Consumer Research, 39(4), 881-898.

Beldad, A., \& Hegner, S. (2018). Determinants of fair trade product purchase intention of Dutch consumers according to the extended theory of planned behaviour. Journal of Consumer Policy, 41(3), 191-210.

Belk, R.W. (1988). Possessions and the extended self. Journal of Consumer Research, 15(2), 139.

Belk, R. (2014). You are what you can access: Sharing and collaborative consumption online. Journal of Business Research, 67(8), 1595-1600.

Black, I. (2010). Sustainability through anti-consumption. Journal of Consumer Behaviour, 9(6), 403-411.

Black, I. R., \& Cherrier, H. (2010). Anti-consumption as part of living a sustainable lifestyle: Daily practices, contextual motivations and subjective values. Journal of Consumer Behaviour, 9(6), 437-453.

Botsman, R., \& Rogers, R. (2010). What's mine is yours: The rise of collaborative consumption. Harper Business.

Brown, K. W., \& Kasser, T. (2005). Are psychological and ecological well-being compatible? The role of values, mindfulness, and lifestyle. Social Indicators Research, 74(2), 349-368.

Brown, S., \& Gray, D. (2016). Household finances and well-being in Australia: An empirical analysis of comparison effects. Journal of Economic Psychology, 53, 17-36.

Bucciol, A., \& Veronesi, M. (2014). Teaching children to save: What is the best strategy for lifetime savings? Journal of Economic Psychology, 45, 1-17.

Burroughs, J. E., \& Rindfleisch, A. (2002). Materialism and well-being: A conflicting values perspective. Journal of Consumer Research, 29(3), 348-370.

Calafell, G., Banqué, N., \& Viciana, S. (2019). Purchase and use of new technologies among young people: Guidelines for sustainable consumption education. Sustainability, 11(6), 1541.

Chaplin, L. N., \& John, D. R. (2007). Growing up in a material world: Age differences in materialism in children and adolescents. Journal of Consumer Research, 34(4), 480-493.

Chatzidakis, A., \& Lee, M. S. W. (2013). Anti-consumption as the study of reasons against. Journal of Macromarketing, 33(3), 190-203.

Cherrier, H., Szuba, M., \& Özçağlar-Toulouse, N. (2012). Barriers to downward carbon emission: Exploring sustainable consumption in the face of the glass floor. Journal of Marketing Management, 28(3-4), 397-419.

Cloutier, J., \& Roy, A. (2020). Consumer credit use of undergraduate, graduate and postgraduate students: An application of the theory of planned behaviour. Journal of Consumer Policy. https://doi.org/10.1007/s10603019-09447-8.

Cohen, M. J. (2007). Consumer credit, household financial management, and sustainable consumption. International Journal of Consumer Studies, 31(1), 57-65. 
Cook, J., Oreskes, N., Doran, P. T., Anderegg, W. R. L., Verheggen, B., Maibach, E. W., et al. (2016). Consensus on consensus: A synthesis of consensus estimates on human-caused global warming. Environmental Research Letters, 11(4), 048002.

de Araujo Gil, L., Leckie, C., \& Johnson, L. (2016). The impact of self on materialism among teenagers. Journal of Consumer Behaviour, 15(3), 281-288.

de Barcellos, M. D., Teixeira, C. M., \& Venturini, J. C. (2014). Personal values associated with political consumption: An exploratory study with university students in Brazil. International Journal of Consumer Studies, 38(2), 207-216.

de Pelsmacker, P., Driesen, L., \& Rayp, G. (2005). Do consumers care about ethics? Willingness to pay for fairtrade coffee. Journal of Consumer Affairs, 39(2), 363-385.

Defila, R., \& Di Giulio, A. (2020). The concept of "consumption corridors" meets society: How an idea for fundamental changes in consumption is received. Journal of Consumer Policy, 43(2), 315-344.

Dittmar, H. (2005). Compulsive buying - a growing concern? An examination of gender, age, and endorsement of materialistic values as predictors. British Journal of Psychology, 96(4), 467-491.

Doran, C. J. (2009). The role of personal values in fair trade consumption. Journal of Business Ethics, 84(4), 549-563.

Duke, L. (2002). Get real!: Cultural relevance and resistance to the mediated feminine ideal. Psychology \& Marketing, 19(2), 211-233.

Effertz, T., Franke, M.-K., \& Teichert, T. (2014). Adolescents' assessments of advertisements for unhealthy food: An example of warning labels for soft drinks. Journal of Consumer Policy, 37(2), 279-299.

Elgin, D., \& Mitchell, A. (1977). Voluntary simplicity. Planning Review, 5(6), 13-15.

Elgin, D., \& Mitchell, A. (2003). Voluntary simplicity: A movement emerges. In D. Doherty, \& A. Etzioni (Eds.), Voluntary simplicity: Responding to consumer culture (pp. 145-174). Oxford: Rowman and Littlefield.

Elliot, V., \& Lindblom, T. (2019). Indebtedness, over-indebtedness and wellbeing. In J. C. Hauff, T. Gärling, \& T. Lindblom (Eds.), Indebtedness in early adulthood (Vol. 34, pp. 21-48). Springer International Publishing.

ESOMAR. (2009). Interviewing children and young people. ESOMAR World Research Codes and Guidelines. https:/www.esomar.org/uploads/public/knowledge-and-standards/codes-and-guidelines/ESOMAR_Codesand-Guidelines_Interviewing-Children-and-Young-People.pdf. Accessed 4 Aug 2020.

Etzioni, A. (1998). Voluntary simplicity: Characterization, select psychological implications, and societal consequences. Journal of Economic Psychology, 19, 619-643.

Fien, J., Neil, C., \& Bentley, M. (2008). Youth can lead the way to sustainable consumption. Journal of Education for Sustainable Development, 2(1), 51-60.

Fischer, D., Böhme, T., \& Geiger, S. M. (2017). Measuring young consumers' sustainable consumption behavior: Development and validation of the YCSCB scale. Young Consumers, 18(3), 312-326.

Fischer, D., Selm, H., Sundermann, A., \& Storksdieck, M. (2020). Storytelling for sustainability. In P. MolthanHill, H. Luna, T. Wall, H. Puntha, \& D. Baden (Eds.), Storytelling for Sustainability in Higher Education (pp. 38-51). Routledge.

Francis, J. E., \& Davis, T. (2015). Adolescents' sustainability concerns and reasons for not consuming sustainably. International Journal of Consumer Studies, 39(1), 43-50.

Frühauf, F., \& Retzmann, T. (2016). Financial literacy in Germany. In C. Aprea, E. Wuttke, K. Breuer, N. K. Koh, P. Davies, B. Greimel-Fuhrmann, et al. (Eds.), International handbook of financial literacy (pp. 263276). Springer.

Fuchs, D., Di Giulio, A., Glaab, K., Lorek, S., Maniates, M., Princen, T., et al. (2016). Power: The missing element in sustainable consumption and absolute reductions research and action. Journal of Cleaner Production, 132, 298-307.

García-de-Frutos, N., Ortega-Egea, J. M., \& Martínez-del-Río, J. (2018). Anti-consumption for environmental sustainability: Conceptualization, review, and multilevel research directions. Journal of Business Ethics, $148(2), 411-435$.

Gärling, T., Michaelsen, P., \& Gamble, A. (2020). Young adults' borrowing to purchases of desired consumer products related to present-biased temporal discounting, attitude towards borrowing and financial involvement and knowledge. International Journal of Consumer Studies, 44(2), 131-139.

Gläser-Zikuda, M., Fuß, S., Laukenmann, M., Metz, K., \& Randler, C. (2005). Promoting students' emotions and achievement: Instructional design and evaluation of the ECOLE-approach. Learning and Instruction, 15(5), $481-495$.

Goldberg, M. E., Gorn, G. J., Peracchio, L. A., \& Bamossy, G. (2003). Understanding materialism among youth. Journal of Consumer Psychology, 13(3), 278-288.

Goodwin, R., Polek, E., \& Bardi, A. (2012). The temporal reciprocity of values and beliefs: A longitudinal study with a major life transition. European Journal of Personality, 26, 360-370. 
Gorge, H., Herbert, M., Özçağlar-Toulouse, N., \& Robert, I. (2015). What do we really need? Questioning consumption through sufficiency. Journal of Macromarketing, 35(1), 11-22.

Grauerholz, L., \& Bubriski-McKenzie, A. (2012). Teaching about consumption: The "not buying it" project. Teaching Sociology, 40(4), 332-348.

Greening, L. A., Greene, D. L., \& Difiglio, C. (2000). Energy efficiency and consumption-the rebound effecta survey. Energy Policy, 28(6-7), 389-401.

Grønhøj, A., \& Thøgersen, J. (2009). Like father, like son? Intergenerational transmission of values, attitudes, and behaviours in the environmental domain. Journal of Environmental Psychology, 29(4), 414-421.

Grønhøj, A., \& Thøgersen, J. (2012). Action speaks louder than words: The effect of personal attitudes and family norms on adolescents' pro-environmental behaviour. Journal of Economic Psychology, 33(1), 292302.

Grunert, K. G., \& Grunert, S. C. (1995). Measuring subjective meaning structures by the laddering method: Theoretical considerations and methodological problems. International Journal of Research in Marketing, 12(3), 209-225.

Guillard, V. (2018). Anticonsumption consciousness in pursuit of sustainability. Journal of Public Policy \& Marketing, 37(2), 274-290.

Gutman, J. (1982). A means-end chain model based on consumer categorization processes. Journal of Marketing, 46(2), 60-72.

Hamari, J., Sjöklint, M., \& Ukkonen, A. (2016). The sharing economy: Why people participate in collaborative consumption. Journal of the Association for Information Science and Technology, 67(9), 2047-2059.

Hawlitschek, F., Teubner, T., \& Gimpel, H. (2018). Consumer motives for peer-to-peer sharing. Journal of Cleaner Production, 204, 144-157.

Hohnen, P., Gram, M., \& Jakobsen, T. B. (2020). Debt as the new credit or credit as the new debt? A cultural analysis of credit consumption among Danish young adults. Journal of Youth Studies, 23(3), 356-370.

Howarth, C. (2017). Informing decision making on climate change and low carbon futures: Framing narratives around the United Kingdom's fifth carbon budget. Energy Research \& Social Science, 31(5), 295-302.

Hume, M. (2010). Compassion without action: Examining the young consumers consumption and attitude to sustainable consumption. Journal of World Business, 45(4), 385-394.

Hüttel, A., Balderjahn, I., \& Hoffmann, S. (2020). Welfare beyond consumption: The benefits of having less. Ecological Economis, 176, 106719.

Hutter, K., \& Hoffmann, S. (2013). Carrotmob and anti-consumption. Journal of Macromarketing, 33(3), 217231.

Iwata, O. (1997). Attitudinal and behavioral correlates of voluntary simplicity lifestyles. Social Behavior and Personality: An International Journal, 25(3), 233-240.

Jackson, T. (2005a). Live better by consuming less?: Is there a "double dividend" in sustainable consumption? Journal of Industrial Ecology, 9(1-2), 19-36.

Jackson, T. (2005b). Motivating sustainable consumption: A review of evidence on consumer behaviour and behavioural change. Sustainable Development Research Network.

Jaeger-Erben, M., Rückert-John, J., \& Schäfer, M. (2015). Sustainable consumption through social innovation: A typology of innovations for sustainable consumption practices. Journal of Cleaner Production, 108, 784 798.

John, D. R. (1999). Consumer socialization of children: A retrospective look at twenty-five years of research. Journal of Consumer Research, 26(3), 183-213.

Joyner Armstrong, C. M., Connell, K. Y. H., Lang, C., Ruppert-Stroescu, M., \& LeHew, M. L. A. (2016). Educating for sustainable fashion: Using clothing acquisition abstinence to explore sustainable consumption and life beyond growth. Journal of Consumer Policy, 39(4), 417-439.

Judson, G. (2015). Supporting ecological understanding through in-depth and imaginative study of a place-based topic or issue. Canadian Journal of Environmental Education, 20, 139-153.

Kadic-Maglajlic, S., Arslanagic-Kalajdzic, M., Micevski, M., Dlacic, J., \& Zabkar, V. (2019). Being engaged is a good thing: Understanding sustainable consumption behavior among young adults. Journal of Business Research, 104(3), 644-654.

Kalmus, V., Keller, M., \& Kiisel, M. (2009). Emerging consumer types in a transition culture: Consumption patterns of generational and ethnic groups in estonia. Journal of Baltic Studies, 40(1), 53-74.

Kamenidou, I. C., Mamalis, S. A., Pavlidis, S., \& Bara, \& Evangelia-Zoi, G. (2019). Segmenting the generation $\mathrm{Z}$ cohort university students based on sustainable food consumption behavior: A preliminary study. Sustainability, 11(3), 837.

Kasser, T. (2005). Frugality, generosity, and materialism in children and adolescents. In K. A. Moore \& L. H. Lippman (Eds.), What do children need to flourish? (pp. 357-373). Springer.

Kemp, E., Cowart, K., \& Bui, M. (2020). Promoting consumer well-being: Examining emotion regulation strategies in social advertising messages. Journal of Business Research, 112, 200-209. 
Kim, N. L., \& Jin, B. E. (2020). Why buy new when one can share? Exploring collaborative consumption motivations for consumer goods. International Journal of Consumer Studies, 44(2), 122-130.

Kozinets, R. V., Handelman, J. M., \& Lee, M. S. W. (2010). Don't read this; or, who cares what the hell anticonsumption is, anyways? Consumption Markets \& Culture, 13(3), 225-233.

Kreuzer, C., Weber, S., Off, M., Hackenberg, T., \& Birk, C. (2019). Shedding light on realized sustainable consumption behavior and perceived barriers of young adults for creating stimulating teaching-learning situations. Sustainability, 11(9), 2587.

Kropfeld, M. I., Nepomuceno, M. V., \& Dantas, D. C. (2018). The ecological impact of anticonsumption lifestyles and environmental concern. Journal of Public Policy \& Marketing, 37(2), 245-259.

Kumar, A., \& Gilovich, T. (2015). Some "thing" to talk about? Differential story utility from experiential and material purchases. Personality and Social Psychology Bulletin, 41(10), 1320-1331.

Lawson, D. F., Stevenson, K., Peterson, M. N., Carrier, S. J., Strnad, R. L., \& Seekamp, E. (2019). Children can foster climate change concern among their parents. Nature Climare Change, 9(6), 458-462.

Leary, R. B., Vann, R. J., Mittelstaedt, J. D., Murphy, P. E., \& Sherry, J. F. (2014). Changing the marketplace one behavior at a time: Perceived marketplace influence and sustainable consumption. Journal of Business Research, 67(9), 1953-1958.

Lee, M. S. W., \& Ahn, C. S. Y. (2016). Anti-consumption, materialism, and consumer well-being. Journal of Consumer Affairs, 50(1), 18-47.

Lee, M. S. W., Fernandez, K. V., \& Hyman, M. R. (2009). Anti-consumption: An overview and research agenda. Journal of Business Research, 62(2), 145-147.

Leonard-Barton, D. (1981). Voluntary simplicity lifestyles and energy conservation. Journal of Consumer Research, 8(3), 243.

Lindblom, A., \& Lindblom, T. (2017). De-ownership orientation and collaborative consumption during turbulent economic times. International Journal of Consumer Studies, 41(4), 431-438.

Lorek, S., \& Fuchs, D. (2013). Strong sustainable consumption governance - precondition for a degrowth path? Journal of Cleaner Production, 38, 36-43.

Lundblad, L., \& Davies, I. A. (2016). The values and motivations behind sustainable fashion consumption. Journal of Consumer Behaviour, 15(2), 149-162.

Luukkanen, L., \& Uusitalo, O. (2019). Toward financial capability-empowering the young. Journal of Consumer Affairs, 53(2), 263-295.

Makarem, S. C., \& Jae, H. (2016). Consumer boycott behavior: An exploratory analysis of twitter feeds. Journal of Consumer Affairs, 50(1), 193-223.

Makri, K., Schlegelmilch, B. B., Mai, R., \& Dinhof, K. (2020). What we know about anticonsumption: An attempt to nail jelly to the wall. Psychology \& Marketing, 37(2), 177-215.

Mathios, A., Micklitz, H. W., Reisch, L. A., Thøgersen, J., \& Twigg-Flesner, C. (2020). Journal of consumer policy's 40th anniversary conference: A forward looking consumer policy research agenda. Journal of Consumer Policy, 43(1), 1-9.

Matthies, E., \& Wallis, H. (2015). Family socialization and sustainable consumption. In L. Reisch \& J. Thøgersen (Eds.), Handbook of Research on Sustainable Consumption (pp. 268-282). Edward Elgar Publishing.

Mau, G., Schramm-Klein, H., \& Reisch, L. (2014). Consumer socialization, buying decisions, and consumer behaviour in children: Introduction to the special issue. Journal of Consumer Policy, 37(2), 155-160.

McEachern, M. G., Middleton, D., \& Cassidy, T. (2020). Encouraging sustainable behaviour change via a social practice approach: A focus on apparel consumption practices. Journal of Consumer Policy, 43(2), 397-418.

McGouran, C., \& Prothero, A. (2016). Enacted voluntary simplicity-exploring the consequences of requesting consumers to intentionally consume less. European Journal of Marketing, 50(1/2), 189-212.

Miles, S., \& Rowe, G. (2004). The laddering technique. In G. M. Breakwell (Ed.), Doing social psychology research (pp. 305-343). Blackwell.

Miles, S., Cliff, D., \& Burr, V. (1998). 'Fitting in and sticking out': Consumption, consumer meanings and the construction of young people's identities. Journal of Youth Studies, 1(1), 81-96.

Möhlmann, M. (2015). Collaborative consumption: Determinants of satisfaction and the likelihood of using a sharing economy option again. Journal of Consumer Behaviour, 14(3), 193-207.

Mont, O. (2004). Institutionalisation of sustainable consumption patterns based on shared use. Ecological Economics, 50(1-2), 135-153.

Montiel, I., Antolin-Lopez, R., \& Gallo, P. J. (2018). Emotions and sustainability: A literary genre-based framework for environmental sustainability management education. Academy of Management Learning \& Education, 17(2), 155-183.

Nepomuceno, M. V., \& Laroche, M. (2015). The impact of materialism and anti-consumption lifestyles on personal debt and account balances. Journal of Business Research, 68(3), 654-664. 
Nepomuceno, M. V., \& Laroche, M. (2017). When materialists intend to resist consumption: The moderating role of self-control and long-term orientation. Journal of Business Ethics, 143(3), 467-483.

Ojala, M. (2008). Recycling and ambivalence. Environment and Behavior, 40(6), 777-797.

Ojala, M. (2012). Hope and climate change: The importance of hope for environmental engagement among young people. Environmental Education Research, 18(5), 625-642.

Olson, J., \& Reynolds, T. (1983). Understanding consumers' cognitive structures: Implications for advertising strategy. In L. Percy \& A. Woodside (Eds.), Advertising and consumer psychology (pp. 77-90). Lexington Books.

Olsson, D., Gericke, N., \& Chang Rundgren, S.-N. (2016). The effect of implementation of education for sustainable development in Swedish compulsory schools: Assessing pupils' sustainability consciousness. Environmental Education Research, 22(2), 176-202.

Ozanne, L. K., \& Ballantine, P. W. (2010). Sharing as a form of anti-consumption? An examination of toy library users. Journal of Consumer Behaviour, 9(6), 485-498.

Palan, K. M., Gentina, E., \& Muratore, I. (2010). Adolescent consumption autonomy: A cross-cultural examination. Journal of Business Research, 63(12), 1342-1348.

Parguel, B., Lunardo, R., \& Benoit-Moreau, F. (2017). Sustainability of the sharing economy in question: When second-hand peer-to-peer platforms stimulate indulgent consumption. Technological Forecasting and Social Change, 125, 48-57.

Pepper, M., Jackson, T., \& Uzzell, D. (2009). An examination of the values that motivate socially conscious and frugal consumer behaviours. International Journal of Consumer Studies, 33(2), 126-136.

Peyer, M., Balderjahn, I., Seegebarth, B., \& Klemm, A. (2017). The role of sustainability in profiling voluntary simplifiers. Journal of Business Research, 70, 37-43.

Pham, T. H., Nguyen, T.,. N., Phan, T. T. H., \& Nguyen, N. T. (2019). Evaluating the purchase behaviour of organic food by young consumers in an emerging market economy. Journal of Strategic Marketing, 27(6), 540-556.

Piacentini, M. G., \& Banister, E. N. (2009). Managing anti-consumption in an excessive drinking culture. Journal of Business Research, 62(2), 279-288.

Poças Ribeiro, A., Harmsen, R., Rosales Carreón, J., \& Worrell, E. (2019). What influences consumption? Consumers and beyond: Purposes, contexts, agents and history. Journal of Cleaner Production, 209, 200215.

Pravet, I., \& Holmlund, M. (2018). Signing up for voluntary simplicity: Consumer motives and effects. Society and Business Review, 13(1), 80-99.

Prothero, A., Dobscha, S., Freund, J., Kilbourne, W. E., Luchs, M. G., Ozanne, L. K., et al. (2011). Sustainable consumption: Opportunities for consumer research and public policy. Journal of Public Policy \& Marketing, 30(1), 31-38.

Räthzel, N., \& Uzzell, D. (2009). Transformative environmental education: A collective rehearsal for reality. Environmental Education Research, 15(3), 263-277.

Reynolds, T. J., \& Gutman, J. (1988). Laddering theory, method, analysis, and interpretation. Journal of Advertising Research, 28(1), 11-31.

Reynolds, T. J., \& Phillips, J. M. (2009). A review and comparative analysis of laddering research methods. In N. K. Malhotra (Ed.), Review of Marketing Research (pp. 130-175). Emerald Group Publishing Limited.

Rich, S. A., Wright, B. J., \& Bennett, P. C. (2020). Development of the voluntary simplicity engagement scale: Measuring low-consumption lifestyles. Journal of Consumer Policy, 43(2), 295-313.

Richins, M. L., \& Dawson, S. (1992). A consumer values orientation for materialism and its measurement: Scale development and validation. Journal of Consumer Research, 19(3), 303-316.

Richter, B., \& Bokelmann, W. (2018). The significance of avoiding household food waste: A means-end-chain approach. Waste Management, 74, 34-42.

Robinson, O. C. (2014). Sampling in interview-based qualitative research: A theoretical and practical guide. Qualitative Research in Psychology, 11(1), 25-41.

Rokeach, M. (1973). The nature of human values. The Free Press.

Rudmin, F. (2016). The consumer science of sharing: A discussant's observations. Journal of the Association for Consumer Research, 1(2), 198-209.

Schaefers, T. (2013). Exploring carsharing usage motives: A hierarchical means-end chain analysis. Transportation Research Part A: Policy and Practice, 47, 69-77.

Schill, M., Godefroit-Winkel, D., \& Hogg, M. K. (2020). Young children's consumer agency: The case of French children and recycling. Journal of Business Research, 110(9), 292-305.

Schneider, F., Kallis, G., \& Martinez-Alier, J. (2010). Crisis or opportunity? Economic degrowth for social equity and ecological sustainability. Introduction to this special issue. Journal of Cleaner Production, 18(6), 511-518.

Schor, J. B. (2004). Born to buy: The commercialized child and the new consumer culture. Scribner. 
Schwartz, S. H. (1992). Universals in the content and structure of values: Theoretical advances and empirical tests in 20 countries. Advances in Experimental Social Psychology, 25, 1-65.

Schwartz, S. H., \& Bilsky, W. (1987). Toward a universal psychological structure of human values. Journal of Personality and Social Psychology, 53(3), 550-562.

Seegebarth, B., Peyer, M., Balderjahn, I., \& Wiedmann, K.-P. (2016). The sustainability roots of anticonsumption lifestyles and initial insights regarding their effects on consumers' well-being. Journal of Consumer Affairs, 50(1), 68-99.

Shaw, D., \& Newholm, T. (2002). Voluntary simplicity and the ethics of consumption. Psychology \& Marketing, 19(2), 167-185.

Sheth, J. N., Sethia, N. K., \& Srinivas, S. (2011). Mindful consumption: A customer-centric approach to sustainability. Journal of the Academy of Marketing Science, 39(1), 21-39.

Shim, S., Barber, B. L., Card, N. A., Xiao, J. J., \& Serido, J. (2010). Financial socialization of first-year college students: The roles of parents, work, and education. Journal of Youth and Adolescence, 39(12), 1457-1470.

Shim, S., Serido, J., Tang, C., \& Card, N. (2015). Socialization processes and pathways to healthy financial development for emerging young adults. Journal of Applied Developmental Psychology, 38, 29-38.

Shove, E., Pantzar, M., \& Watson, M. (2012). The Dynamics of Social Practice. Sage.

Shrivastava, P. (2010). Pedagogy of passion for sustainability. Academy of Management Learning \& Education, $9(3), 443-455$.

Slater, J., Falkenberg, T., Rutherford, J., \& Colatruglio, S. (2018). Food literacy competencies: A conceptual framework for youth transitioning to adulthood. International Journal of Consumer Studies, 42(5), 547-556.

Soper, K. (2007). Conceptualizing needs in the context of consumer politics. Journal of Consumer Policy, 29(4), $355-372$.

Sotiropoulos, V., \& d'Astous, A. (2012). Social networks and credit card overspending among young adult consumers. Journal of Consumer Affairs, 46(3), 457-484.

Sotiropoulos, V., \& d'Astous, A. (2013). Attitudinal, self-efficacy, and social norms determinants of young consumers' propensity to overspend on credit cards. Journal of Consumer Policy, 36(2), 179-196.

Stanes, E., Klocker, N., \& Gibson, C. (2015). Young adult households and domestic sustainabilities. Geoforum, $65,46-58$.

Steinmetz, H., Knappstein, M., Ajzen, I., Schmidt, P., \& Kabst, R. (2016). How effective are behavior change interventions based on the theory of planned behavior? Zeitschrift für Psychologie, 224(3), 216-233.

Sunstein, C. R., \& Reisch, L. A. (2019). Trusting nudges: Toward a bill of rights for nudging. Routledge advances in behavioural economics and finance. Routledge.

Sweet, E., Nandi, A., Adam, E. K., \& McDade, T. W. (2013). The high price of debt: Household financial debt and its impact on mental and physical health. Social Science \& Medicine, 91, 94-100.

Sweeting, H., Hunt, K., \& Bhaskar, A. (2012). Consumerism and well-being in early adolescence. Journal of Youth Studies, 15(6), 802-820.

Te'eni-Harari, T. (2014). Clarifying the relationship between involvement variables and advertising effectiveness among young people. Journal of Consumer Policy, 37(2), 183-203.

Thøgersen, J. (2005). How may consumer policy empower consumers for sustainable lifestyles? Journal of Consumer Policy, 28(2), 143-177.

Thøgersen, J. (2010). Country differences in sustainable consumption: The case of organic food. Journal of Macromarketing, 30(2), 171-185.

Thøgersen, J., \& Ölander, F. (2002). Human values and the emergence of a sustainable consumption pattern: A panel study. Journal of Economic Psychology, 23(5), 605-630.

Thøgersen, J., \& Schrader, U. (2012). From knowledge to action-New paths towards Sustainable Consumption. Journal of Consumer Policy, 35(1), 1-5.

Tinson, J., \& Nuttall, P. (2011). Performing the high-school prom in the UK: Locating authenticity through practice. Journal of Marketing Management, 27(9-10), 1007-1026.

Tinson, J., Close, A., Tuncay Zayer, L., \& Nuttall, P. (2013). Attitudinal and behavioral resistance: A marketing perspective. Journal of Consumer Behaviour, 12(6), 436-448.

Tran, A. G. T. T., Mintert, J. S., Llamas, J. D., \& Lam, C. K. (2018). At what costs? Student loan debt, debt stress, and racially/ethnically diverse college students' perceived health. Cultural Diversity and Ethnic Minority Psychology, 24(4), 459-469.

UNESCO-UNEP. (2007). YouthXchange: Training kit on sustainable consumption. United Nations Educational, Scientific and Cultural Organization, and United Nations Environment Programme.

United Nations. (2015). Goal 12: Ensure sustainable consumption and production patterns. http://www.un.org/ sustainabledevelopment/sustainable-consumption-production/. Accessed 4 Aug 2020.

United Nations. (2018). World youth report. Youth and the agenda 2030 for sustainable development. United Nations. 
Vantamay, N. (2018). Investigation and recommendations on the promotion of sustainable consumption behavior among young consumers in Thailand. Kasetsart Journal of Social Sciences, 39(1), 51-58.

Veland, S., Scoville-Simonds, M., Gram-Hanssen, I., Schorre, A. K., El Khoury, A., Nordbø, M. J., et al. (2018). Narrative matters for sustainability: The transformative role of storytelling in realizing $1.5^{\circ} \mathrm{C}$ futures. Current Opinion in Environmental Sustainability, 31, 41-47.

Ward, S. (1974). Consumer socialization. Journal of Consumer Research, 1(2), 1-14.

Webley, P., \& Nyhus, E. K. (2013). Economic socialization, saving and assets in European young adults. Economics of Education Review, 33, 19-30.

Wilska, T.-A. (2003). Mobile phone use as part of young people's consumption styles. Journal of Consumer Policy, 26(4), 441-463.

$\mathrm{Xu}$, Y., Chen, Y., Burman, R., \& Zhao, H. (2014). Second-hand clothing consumption: A cross-cultural comparison between American and Chinese young consumers. International Journal of Consumer Studies, 38(6), 670-677.

Yuksel, U., \& Mryteza, V. (2009). An evaluation of strategic responses to consumer boycotts. Journal of Business Research, 62(2), 248-259.

Zavestoski, S. (2002). The social-psychological bases of anticonsumption attitudes. Psychology \& Marketing, 19(2), 149-165.

Ziesemer, F., Hüttel, A., \& Balderjahn, I. (2019). Pioneers' insights into governing social innovation for sustainable anti-consumption. Sustainability, 11(23), 6663.

Publisher's Note Springer Nature remains neutral with regard to jurisdictional claims in published maps and institutional affiliations. 